\title{
Superplastic Alumina Ceramics with Grain Growth Inhibitors
}

\author{
Liang A. Xue,* Xin Wu,* and I-Wei Chen* \\ Department of Materials Science and Engineering, The University of Michigan, \\ Ann Arbor, Michigan 48109-2136
}

\begin{abstract}
Superplastic deformation of alumina ceramics was studied at $1400^{\circ}$ to $1450^{\circ} \mathrm{C}$ and at a strain rate of $4 \times 10^{-5}$ to $5 \times$ $10^{-4} \mathrm{~s}^{-1}$. MgO and $\mathrm{ZrO}_{2}$ were introduced to suppress dynamic grain growth. The latter was especially effective; grain growth was minimal in 10-vol\%- $\mathrm{ZrO}_{2}$-containing material. Both materials were superplastically stretched under biaxial tension to $100 \%$ engineering strain with good surface finishing, demonstrating the feasibility of superplastic forming for alumina ceramics. [Key words: alumina, superplastic, deformation, grain growth, additives.]
\end{abstract}

\section{Introduction}

$\mathbf{I}_{\mathrm{s}}$ A previous paper, ${ }^{1}$ we showed that, for pure alumina, grain growth during sintering was effectively suppressed through low-temperature sintering. Nevertheless, dynamic grain growth occurred rapidly in superplastic deformation. The latter had a devastating effect on the superplastic behavior of the material. Although the aforementioned ultra-finegrained pure alumina exhibited rather low initial flow stresses at relatively low temperatures and hence might have been a good candidate for superplastic ceramic, this was not realized because the dynamic grain growth caused strainhardening leading to cavitation and cracking. Therefore, it became clear that the control of dynamic grain growth was an essential next step in the development of superplastic alumina ceramics.

The phenomenon of dynamic grain growth during superplastic deformation of fine-grained ceramics has been well documented..$^{2-7}$ However, its cause and remedy are not yet clear. Following the previous work in the literature on sintering and static grain growth, we have added $\mathrm{MgO}^{8}$ and $\mathrm{ZrO}_{2}{ }^{9}$ to alumina in an attempt to lower the grain-boundary mobility through solute drag $(\mathrm{MgO})$ or second-phase pinning $\left(\mathrm{ZrO}_{2}\right),{ }^{10}$ thereby suppressing dynamic grain growth. These approaches have proved successful. As a result, superplastic alumina ceramics deformable under biaxial tension have been obtained.

\section{Experimental Procedure}

The procedure for material preparation was essentially the same as that reported previously, ${ }^{1}$ except for an additional step of introducing additives to pure alumina. This was done by adding an aqueous solution of either $\mathrm{Mg}\left(\mathrm{NO}_{3}\right)_{2}$ or $\mathrm{ZrOCl}_{2}$ to a dispersed suspension of alumina powders in distilled water. The $\mathrm{pH}$ of the mixture was then adjusted to floc the suspension. The amount of $\mathrm{MgO}$ introduced was $200 \mathrm{ppm}$, a

R. Raj-contributing editor

\footnotetext{
Manuscript No. 197355. Received August 17, 1990; approved December 7, 1990.

Presented at the 92nd Annual Meeting of the American Ceramic Society, Dallas, TX, April 23, 1990 (Paper No. 5-JV-90).

Supported by the U.S. Army Research Office under Contract No. DAALO3-89-KO133.

*Member, American Ceramic Society.
}

value around the solubility limit. ${ }^{11}$ The volume fraction of $\mathrm{ZrO}_{2}$ addition was $10 \%\left(\mathrm{ZrO}_{2}\right.$ and $\mathrm{Al}_{2} \mathrm{O}_{3}$ have little solubility for each other). The slurry was dried and calcined $\left(700^{\circ} \mathrm{C}\right.$ for $\mathrm{MgO}$-doped alumina and $1000^{\circ} \mathrm{C}$ for $\mathrm{ZrO}_{2}$-containing alumina). The powder thus obtained was again milled, dispersed and pressure-cast into cakes as described elsewhere. ${ }^{12}$ The sintering temperatures used were $1320^{\circ} \mathrm{C}$ for $\mathrm{MgO}$-doped alumina and $1480^{\circ} \mathrm{C}$ for $\mathrm{ZrO}_{2}$-added alumina, compared to $1250^{\circ} \mathrm{C}$ for pure alumina. A final density of greater than $98 \%$ of the theoretical was reachable in $2 \mathrm{~h}(4 \mathrm{~h}$ in the case of pure alumina). Other experimental procedures for specimen preparation, compression testing, superplastic stretching, and microstructural characterization were the same as reported previously. ${ }^{1,12,13}$ For $\mathrm{ZrO}_{2}$-added alumina, the average linear intercept length was corrected for a second phase using the method of Wurst and Nelson. ${ }^{14}$

\section{Results and Discussion}

\section{(1) Sintered Microstructures}

Polished cross sections of sintered samples of pure alumina, MgO-doped alumina, and $\mathrm{ZrO}_{2}$-added alumina are shown in Figs. 1(A), (B), and (C), respectively. Both undoped and MgO-doped aluminas show typical microstructures of a singlephase material, although the grain size distribution in undoped alumina appears somewhat wider. In $\mathrm{ZrO}_{2}$-added material, small $\mathrm{ZrO}_{2}$ inclusions are well distributed, lying almost exclusively at alumina grain triple junctions. The average grain sizes of these specimens were $0.51 \mu \mathrm{m}$ for undoped, $0.53 \mu \mathrm{m}$ for $\mathrm{MgO}$-doped, and $0.50 \mu \mathrm{m}$ for $\mathrm{ZrO}_{2}$-added alumina. Apparently, during low-temperature sintering, grain size seems not to have been further reduced by these additives. (As shown previously, static grain growth in alumina at temperatures below $1300^{\circ} \mathrm{C}$ was already very slow. ${ }^{1}$ )

\section{(2) Effect of Additives on Deformation and Grain Growth}

True stress versus true strain curves at $1400^{\circ} \mathrm{C}$ and a constant strain rate of $10^{-4} / \mathrm{s}$ in compression are shown in Fig. 2 for pure, $\mathrm{MgO}$-doped, and $\mathrm{ZrO}_{2}$-added alumina. Extensive strain hardening was evident only for pure alumina. As discussed in the previous paper, ${ }^{1}$ the strain hardening can be attributed to dynamic grain growth. (The drop of stress at large strain is due to severe cavitation which is more pronounced here than that at lower temperature and lower strain rate. ${ }^{1}$ ) Compared to pure alumina, strain hardening for $\mathrm{MgO}$ doped alumina is modest; its flow stress increased from an initial value of about $20 \mathrm{MPa}$ to some $50 \mathrm{MPa}$ after a deformation strain of 0.68 . Strain hardening can be totally suppressed by $10 \% \mathrm{ZrO}_{2}$ addition. Indeed, although the initial flow stress of $\mathrm{ZrO}_{2}$-containing alumina is the highest, it becomes comparable to those of the other two aluminas at large strains.

Data of flow stress and strain rate at $1400^{\circ} \mathrm{C}$ for undoped, $\mathrm{MgO}$-doped, and $\mathrm{ZrO}_{2}$-added alumina are summarized in Fig. 3. Because of pronounced dynamic grain growth in pure alumina, flow stress at $2 \%$ strain was used here for comparison. Since the initial grain sizes were nearly the same for the three materials, these data can be compared directly with each other. A common feature of these data is a stress expo- 


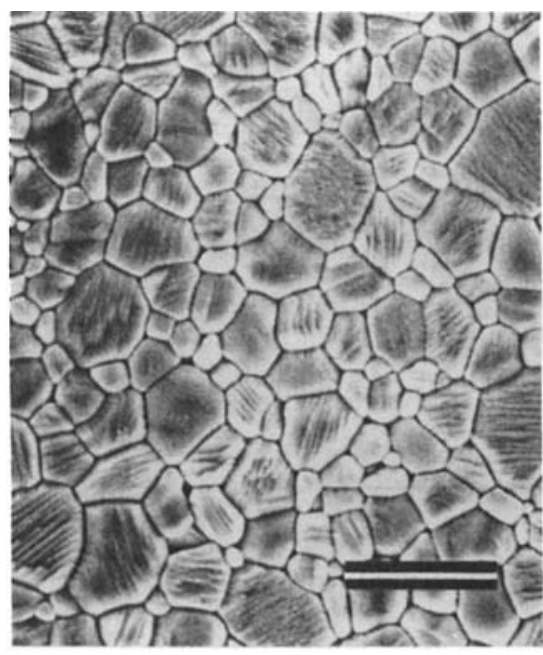

(A)

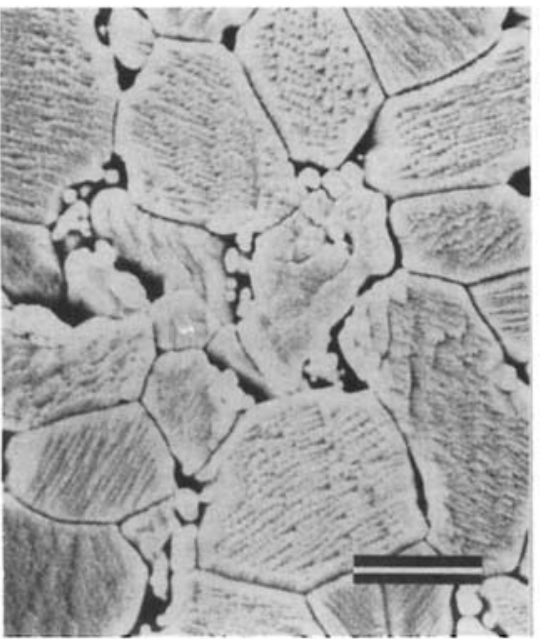

(D)

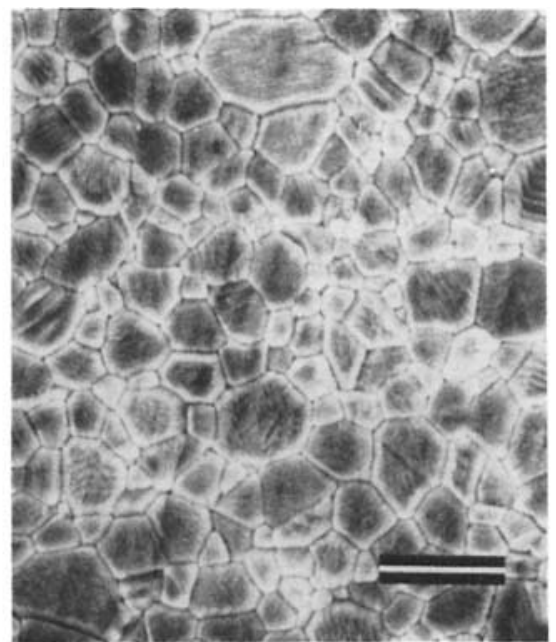

(B)

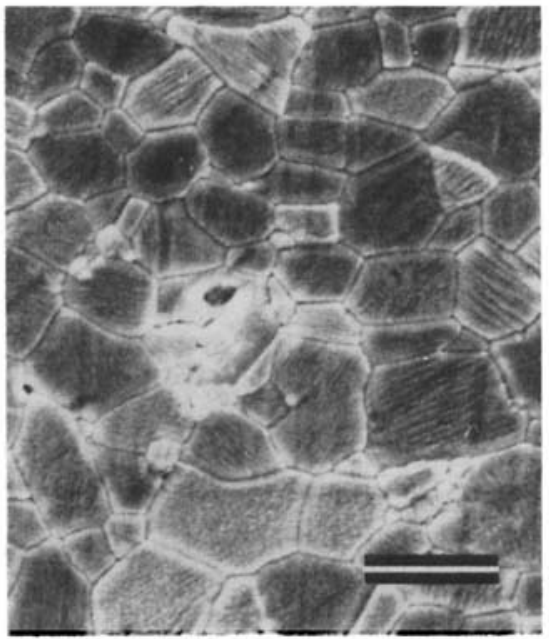

(E)

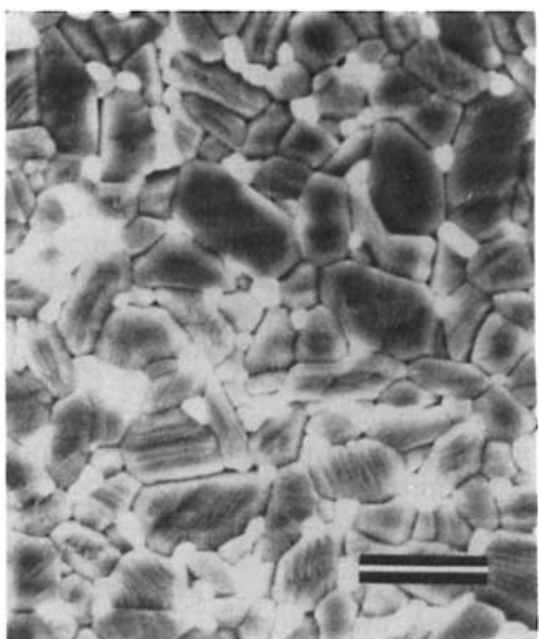

(C)

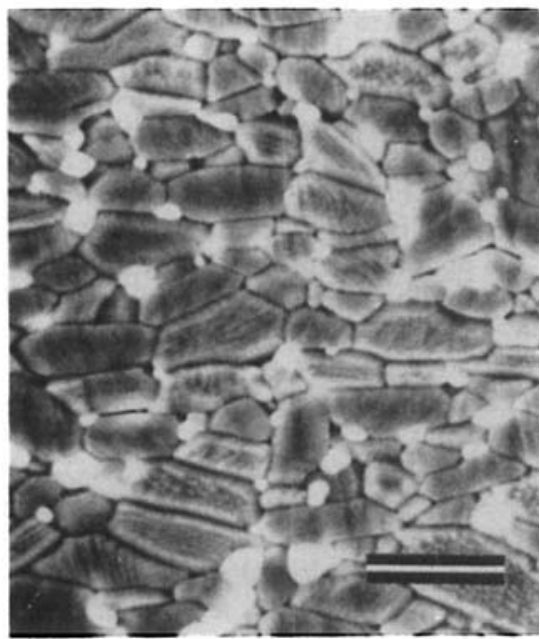

(F)

Fig. 1. Scanning electron micrographs of polished cross sections of various aluminas (bar $=1 \mu \mathrm{m})$. As-sintered specimens: (A) pure; (B) $\mathrm{MgO}$-doped; (C) $\mathrm{ZrO}_{2}$-added. Deformed at $1400^{\circ} \mathrm{C}, 10^{-4} / \mathrm{s}$ : (D) pure, $\epsilon=0.57$; (E) $\mathrm{MgO}$-doped, $\epsilon=0.68 ;(\mathrm{F}) \mathrm{ZrO}_{2}$-added; $\epsilon=0.68$.

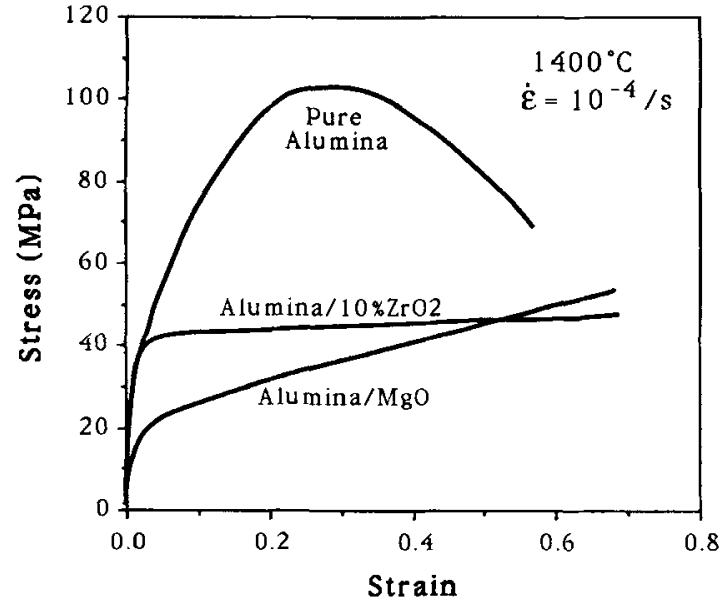

Fig. 2. Flow stress at a constant strain rate of $10^{-4} / \mathrm{s}$ versus strain curves for pure, $\mathrm{MgO}$-doped, and $\mathrm{ZrO}_{2}$-added alumina.

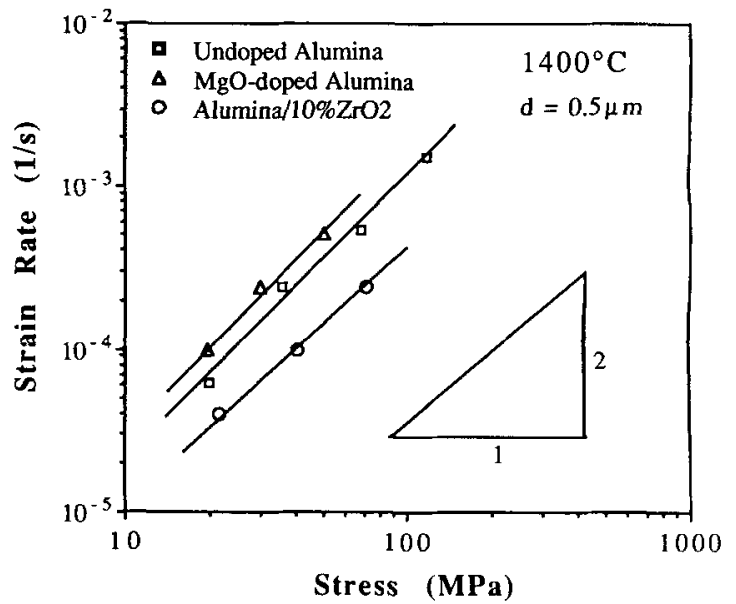

Fig. 3. Relationship between strain rate and flow stress at $2 \%$ strain at $1400^{\circ} \mathrm{C}$ for pure, $\mathrm{MgO}$-doped, and $\mathrm{ZrO}_{2}$-added alumina. 
nent near 2. This would suggest that the additives do not change the deformation mechanism of alumina if the same microstructure is maintained under these deformation conditions. A small increase of strain rate due to $\mathrm{MgO}$ is observed, as is the depression of strain rate due to $\mathrm{ZrO}_{2}$. These observations are in agreement with Cannon et al.'s work on pure and $\mathrm{MgO}$-doped fine-grained alumina, ${ }^{15}$ and with Wakai et al.'s study on pure and $\mathrm{ZrO}_{2}$-added alumina. ${ }^{16}$

The corresponding microstructures of these materials after deformation are shown in Figs. 1(D) (undoped), 1(E) (MgOdoped), and $1(\mathrm{~F})\left(\mathrm{ZrO}_{2}\right.$-added). Extensive grain growth is evident by comparing Figs. 1(A) and (D) for pure alumina. The grain growth for $\mathrm{MgO}$-doped alumina is less pronounced. The grain size in the $\mathrm{ZrO}_{2}$-added material remains almost unchanged despite its change in the aspect ratio.

The evolution of grain size during deformation is further illustrated in Fig. 4, in which the normalized alumina grain size data, in the form of $\ln \left(d / d_{0}\right)$, are plotted against strain. Here $d$ is the current grain size and $d_{0}$ is the initial grain size. Also included are the two datum points of Mocellin et al. ${ }^{5}$ and the data of Venkatachari and $\mathrm{Raj}^{17}$ for $\mathrm{MgO}$-doped alumina of a coarser grain size. These data clearly show the grain growth retardation effect of $\mathrm{MgO}$ and $\mathrm{ZrO}_{2}$. For the case of $\mathrm{MgO}$ doping, the data from three independent studies are generally in agreement with each other. However, the data of Venkatachari and Raj show somewhat less grain growth than those found in the present study and in Mocellin et al.'s work. This is not surprising since in the former the amount of $\mathrm{MgO}$ employed was $0.25 \mathrm{wt} \%$ in contrast to $200 \mathrm{ppm}$ in the present study and $500 \mathrm{ppm}$ in Mocellin et al.'s work. (The former concentration is well over the solubility of $\mathrm{MgO}$ in alumina; ${ }^{11}$ thus second-phase pinning may well be operative.)

Static grain growth also occurred to some extent during the deformation. This can be noted from the data in Fig. 4; none of these lines except that of $\mathrm{ZrO}_{2}$-added alumina seems to pass the origin. Nevertheless, the main contribution to the grain size increase was from dynamic grain growth. For example, for undoped alumina of an initial grain size of $0.51 \mu \mathrm{m}$ at $1400^{\circ} \mathrm{C}$, a deformed specimen (strain rate $=$ $3 \times 10^{-4} / \mathrm{s}$ for $2 \times 10^{3} \mathrm{~s}$ ) has $d=1.6 \mu \mathrm{m}$, while an annealed specimen reached $d=0.9 \mu \mathrm{m}$ over the same time period. In the case of $\mathrm{MgO}$-doped alumina at $1420^{\circ} \mathrm{C},{ }^{17}$ deformation to a strain of 0.66 increased grain size from 1.6 to $3.05 \mu \mathrm{m}$, whereas in the same period $(186 \mathrm{~min})$, the grain size of an annealed sample reached only $1.8 \mu \mathrm{m}$.

Finally, to investigate the cause of elongated grains formed during deformation of $\mathrm{ZrO}_{2}$-added material, we have per-

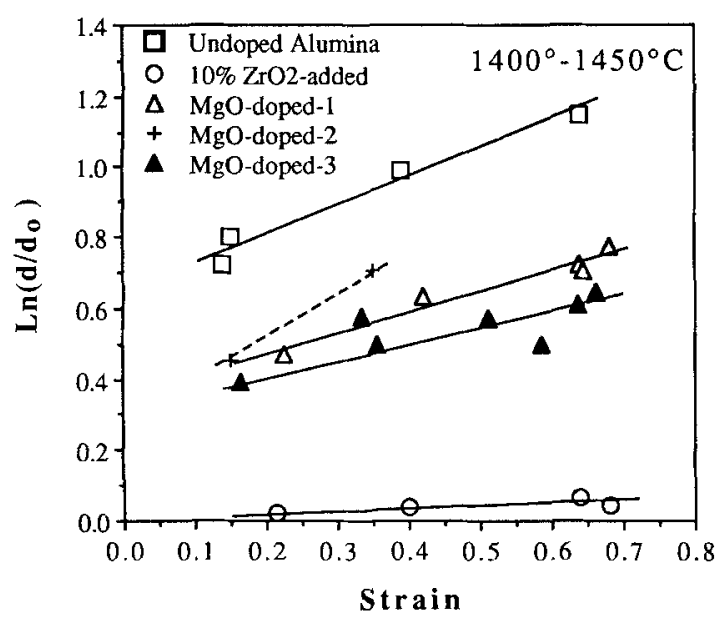

Fig. 4. Normalized grain size (see text) versus strain for various aluminas. Data of $\mathrm{MgO}$-doped-1 are of this study, those of $\mathrm{MgO}$ doped-2 are of Mocellin et al. (Ref. $5, d_{0}=1.17 \mu \mathrm{m}$ ), and those of MgO-doped-3 are of Venkatachari and Raj (Ref. $17, d_{0}=1.6 \mu \mathrm{m}$ ).

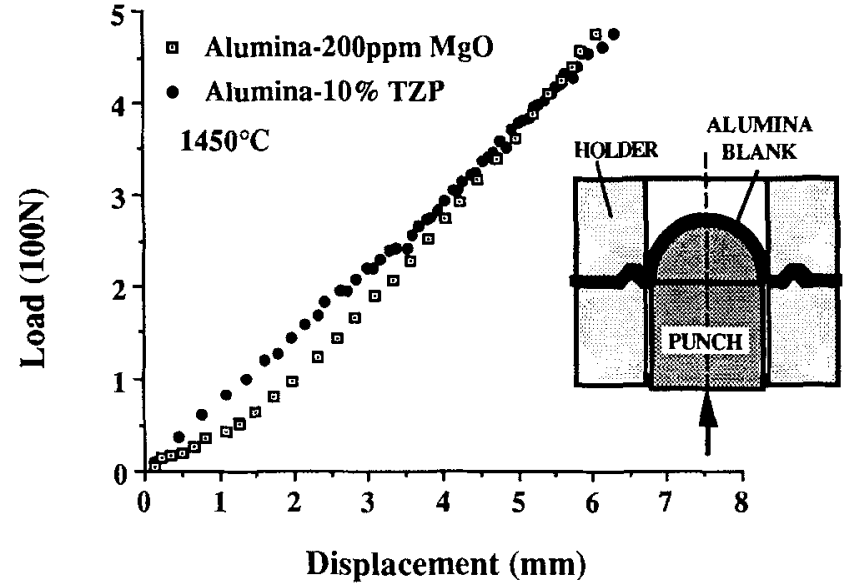

Fig. 5. Forming load versus punch displacement for $\mathrm{MgO}$-doped and $\mathrm{ZrO}_{2}$-added alumina during superplastic stretching at $1450^{\circ} \mathrm{C}$. The average strain rate is $3 \times 10^{-4} / \mathrm{s}$ for the former and $1.5 \times 10^{-4} / \mathrm{s}$ for the latter.

formed additional deformation experiments over a wide range of strain rate and temperature to large strains on the three aluminas shown in Fig. 1 . In addition, a $\mathrm{ZrO}_{2}$-added alumina which was further doped with $1000 \mathrm{ppm} \mathrm{MgO}$ was also tested. We have found that the extent of grain elongation was consistent with the magnitude of the flow stress. Thus, for example, at a constant strain rate and total strain, grains were more elongated at lower temperatures, while $\mathrm{MgO}$ doping to $\mathrm{ZrO}_{2}$ containing alumina lowered both the flow stress and the grain elongation. At the same flow stress, a higher temperature gave rise to a larger aspect ratio. These observations suggest that an increased dislocation activity, which is more sensitive to flow stress than diffusional superplastic flow, is probably responsible for grain elongation, and the higher aspect ratio of $\mathrm{ZrO}_{2}$-added alumina is due to its higher flow stress during much of the earlier stage of deformation as indicated in Fig. 2.

\section{(3) Superplastic Stretching}

We have verified the superplastic formability of $\mathrm{MgO}$ doped and $\mathrm{ZrO}_{2}$-added alumina, using the punch bulging test described elsewhere. ${ }^{13}$ In this test, a flat disk is stretched by a semispherical punch to a dome shape. When the height of the dome reaches the same as the dome radius, the surface area is approximately twice that of the original. This corresponds to a biaxial engineering strain of $100 \%$.

Typical curves of forming load versus punch displacement for $\mathrm{MgO}$-doped and $\mathrm{ZrO}_{2}$-added aluminas at $1450^{\circ} \mathrm{C}$ are

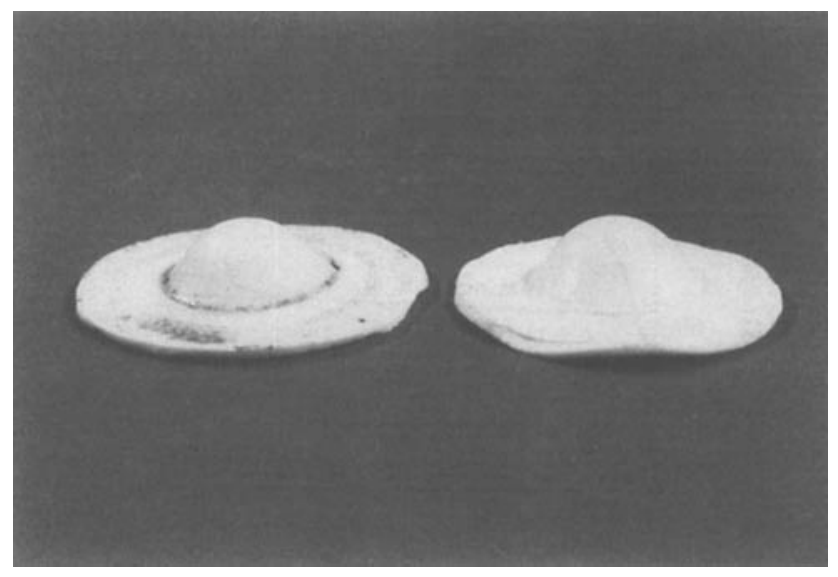

Fig. 6. Superplastic-stretched alumina disks: (left) $\mathrm{MgO}$-doped; (right) $\mathrm{ZrO}_{2}$-added. 
shown in Fig. 5. The punch radius used was $6.5 \mathrm{~mm}$. The average strain rate was $3 \times 10^{-4} / \mathrm{s}$ for $\mathrm{MgO}$-doped alumina and $1.5 \times 10^{-4} / \mathrm{s}$ for $\mathrm{ZrO}_{2}$-added alumina. The increase in load with the displacement in the case of $\mathrm{ZrO}_{2}$-added sample is due essentially to the increase in the deforming area of the specimen, since grain growth/strain hardening is negligible in this material. In comparison, the $\mathrm{MgO}$-doped sample showed a lower load in the early stage but a more rapid load increase at the later stage, which is consistent with its lower initial flow stress and faster dynamic grain growth as already discussed earlier.

In both cases, full stretching to a half-spherical-shaped dome was successfully completed. Figure 6 shows photographs of two punch-stretched specimens, with $\mathrm{MgO}$-doped alumina on the left and $\mathrm{ZrO}_{2}$-added alumina on the right. The quality of the as-formed surfaces is good. This demonstrates that, once dynamic grain growth is suppressed, deformation processing of alumina ceramics should be feasible.

\section{References}

${ }^{1}$ L. A. Xue and I-W. Chen, "Deformation and Grain Growth of LowTemperature-Sintered High-Purity Alumina," J. Am. Ceram. Soc., 73 [11] 3518-21 (1990).

${ }^{2}$ F. Wakai, S. Sakaguchi, and H. Kato, "Compressive Deformation Properties and Microstructures in the Superplastic Y-TZP," J. Ceram. Soc. Jpn., 94, $72-75$ (1986).

${ }^{3}$ L. A. Xue and R. Raj, "Superplastic Deformation of Zinc Sulfide near Its Transformation Temperature $\left(1020^{\circ} \mathrm{C}\right)$," J. Am. Ceram. Soc., 72 [10] 1792-96 (1989).

${ }^{4}$ T.-G. Nieh and J. Wadsworth, "Dynamic Grain Growth During Superplastic Deformation of Yttria-Stabilized Tetragonal Zirconia Polycrystals,"
J. Am. Ceram. Soc., 72 [8] 1469-72 (1989).

${ }^{5}$ J. D. Fridez, C. Carry, and A. Mocellin, "Effects of Temperature and Stress on Grain-Boundary Behavior in Fine-Grained Alumina"; pp. 720-40 in Advances in Ceramics, Vol. 10, Structure and Properties of $\mathrm{MgO}$ and $\mathrm{Al}_{2} \mathrm{O}_{3}$ Ceramics. Edited by W. D. Kingery. American Ceramic Society, Columbus, $\mathrm{OH}, 1984$.

${ }^{6} \mathrm{C}$. Carry and A. Mocellin, "Example of Superplastic Forming FineGrained $\mathrm{Al}_{2} \mathrm{O}_{3}$ and $\mathrm{ZrO}_{2}$ Ceramics"; pp. 1043-1052 in High Tech Ceramics. Edited by P. Vincenzini. Elsevier Science Publishers B.V., Amsterdam, Netherlands, 1987.

${ }^{7}$ C. Carry and A. Mocellin, "Structural Superplasticity in Single Phase Crystalline Ceramics," Ceram. Int., 13, 89-98 (1987).

${ }^{8}$ S. J. Bennison and M.P. Harmer, "Grain-Growth Kinetics for Alumina in the Absence of a Liquid Phase," J. Am. Ceram. Soc., 68 [1] C-22-C-24 (1985).

${ }^{9} \mathrm{~F}$. F. Lange and M. M. Hirlinger, "Hindrance of Grain Growth in $\mathrm{Al}_{2} \mathrm{O}_{3}$ by $\mathrm{ZrO}_{2}$ Inclusions," J. Am Ceram. Soc., 67 [3] 164-68 (1984).

${ }^{10}$ R. J. Brook, "Controlled Grain Growth," Treatise Mater. Sci. Technol., 9 , 331-64 (1976).

"S. K. Roy and R. L. Coble, "Solubilities of Magnesia, Titania and Magnesium Titanate in Aluminum Oxide," J. Am. Ceram. Soc., 51 [1] 1-6 (1968).

${ }^{12}$ C-M. J. Hwang and I-W. Chen, "Effect of a Liquid Phase on Superplasticity of 2-mol\%-Y $\mathrm{O}_{3}$-Stabilized Tetragonal Zirconia Polycrystals," J. Am. Ceram. Soc., 73 [6] 1626-32 (1990).

${ }^{13} \mathrm{X}$. Wu and I-W. Chen, "Superplastic Bulging of Fine-Grained Zirconia," J. Am. Ceram. Soc., 73 [3] 746-49 (1990).

${ }_{14}$ J. C. Wurst and J. A. Nelson, "Lineal Intercept Technique for Measuring Grain Size in Two-Phase Polycrystalline Ceramics," J. Am. Ceram. Soc., 55 [2] 109 (1972).

${ }^{i 5}$ R. M. Cannon, W. H. Rhodes, and A. H. Heuer, "Plastic Deformation of Fine-Grained Alumina $\left(\mathrm{Al}_{2} \mathrm{O}_{3}\right):$ I, Interface-Controlled Diffusional Creep," J. Am. Ceram. Soc., 63 [1-2] 46-53 (1980).

${ }^{16} \mathrm{~F}$. Wakai, T. Iga, and T. Nagano, "Effect of Dispersion of $\mathrm{ZrO}_{2}$ Particles on Creep of Fine-Grained $\mathrm{Al}_{2} \mathrm{O}_{3}$," J. Ceram. Soc. Jpn., 96 [12] 1206-209 (1988).

${ }^{17}$ K. R. Venkatachari and R. Raj, "Superplastic Flow in Fine-Grained Alumina," J. Am. Ceram. Soc., 69 [2] 135-38 (1986). 